\title{
Acute cardiovascular effects of ethanol A controlled non-invasive study
}

\author{
MARKKU KUPARI
}

From the Cardiovascular Laboratory, Helsinki University Central Hospital and the Research Laboratories of the Finnish State Alcohol Monopoly (Alko), Helsinki, Finland

SUMMARY The acute cardiac effects of ethanol ( $1 \mathrm{~g} / \mathrm{kg}$ orally within 60 minutes) were examined in $22 \mathrm{i}$ healthy volunteers (11 men and 11 women) by M-mode echocardiography and systolic time intervals $\vec{v}$ for three hours after beginning ingestion. Each subject also took part in a control study, in which the same volume of juice was substituted for ethanol.

Heart rate increased by $15 \%$ and cardiac output by $17 \%$ during ethanol intake, while total $\vec{T}$ peripheral resistance decreased by $15 \%$. Left ventricular end-diastolic diameter was shortened by $\frac{\mathbb{D}}{2}$ $2 \%$ during the declining phase of blood ethanol concentration; stroke volume and circumferential wall stress were simultaneously decreased by $7 \%$ and $5 \%$, respectively. No ethanol-related changes $₹$ were noted in echocardiographic indices of left ventricular function, neither were any sex differences $\vec{\oplus}$ observed in the cardiovascular changes after ethanol ingestion.

Each of the systolic time intervals was significantly altered even during the control experiment. The responses of each of these intervals to ethanol differed significantly from those in the control test as well. Notably, the pre-ejection period/ejection time ratio rose after ethanol, this change, accord- 0 ing to simultaneous echocardiographic data, resulting from reduced preload instead of impaired $\stackrel{\otimes}{\infty}$ contractility, as maintained in previous investigations.

It is concluded that alcohol in modest doses is capable of altering each of the extramyocardial $\overrightarrow{\vec{O}}$ influences on left ventricular function - heart rate, preload, and afterload - but does not impair 3 myocardial performance, at least in normal subjects.

The concept of alcohol as a myocardial toxin has been generally accepted by cardiologists. Few would disagree that the chronic and excessive use of alcohol may result in clinically significant heart muscle disease. ${ }^{1}$ Also widely endorsed is the view that alcohol, even in social amounts, brings about an acute, reversible cardiac depression ${ }^{1}$ but this is much more controversial and, in fact, alcohol has been claimed to exert beneficial ${ }^{2}$ as well as harmful ${ }^{3}$ effects on left ventricular function in patients with heart disease. This contradiction pertains also to normal subjects, in whom alcohol ingestion has been reported to cause myocardial depression, ${ }^{4-6}$ no effect, $^{78}$ or an enhancement of cardiac performance. ${ }^{3}$ The suggested sex difference is also strange: female hearts escape both the injurious effects of alcohol in chronic use ${ }^{9}$ and its acute myocardial depressive actions. ${ }^{10}$

This study was designed to assess the acute cardiac effects of alcohol in normal subjects, compared with Accepted for publication 3 September 1982 those of juice ingestion, by using echocardiography and systolic time intervals.

\section{Subjects and methods}

The study group consisted of 22 volunteers, 11 men and 11 women, with a mean age of 23 years (range 20 을 to 27 ). All were healthy as shown by the medical history, physical examination, a 12 lead electrocardio- $O$ gram, and baseline echocardiogram. They were infre- $N$ quent or moderate drinkers, with a mean reported N alcohol consumption of $8 \mathrm{~g}$ /day (range 1 to 30). Aparto from hormonal contraception (three subjects), noneo was using any drugs either regularly or occasionally.

\section{STUDY DESIGN}

The subjects entered the laboratory at 7:00 to 7:30 in the morning after an overnight fast and having ab- $-\overline{\mathrm{D}}$ stained from alcoholic beverages for at least two days 
beforehand. An indwelling venous catheter was inserted, whereupon the subjects rested supine for $\mathbf{3 0}$ minutes. Control sphygmomanometric arterial blood pressure, an echocardiogram of the left ventricle, systolic time intervals, and a venous blood sample for ethanol determination were then taken. The subjects then ingested ethanol $1 \mathrm{~g} / \mathrm{kg}$ body weight as a $15 \%$ $(w / v)$ juice diluted solution within 60 minutes. The above measurements were repeated $30,60,90,120$, and 180 minutes after the first drink. The subjects were lying supine during the entire study period. Each subject also took part in a control experiment designed identically to that presented above, with the exception that ethanol was replaced by an isovolumic amount (average $430 \mathrm{ml}$ ) of pure juice.

\section{ECHOCARDIOGRAPHY}

The echocardiographic examinations were performed using an Irex System II ultrasonograph equipped with a fibreoptic strip-chart recorder and a $2.25 \mathrm{MHz}$ medium focused transducer. $M$-mode echoes from the left ventricle were recorded during quiet respiration by the standard technique ${ }^{11}$ simultaneously with lead II of the electrocardiogram and an external phonocardiogram on dry silver paper at a speed of $100 \mathrm{~mm} / \mathrm{s}$. High quality recordings were not obtained in one male and two female subjects, and the echocardiographic data are thus based on the recordings obtained in the remaining 19 subjects.

The echocardiograms were analysed semiautomatically using an $x$-y digitiser and a PDP $11 / 30$ computer according to the method described by Upton and Gibson. ${ }^{12}$ Left ventricular end-diastolic diameter and end-systolic diameter were measured by the European standardisation. ${ }^{13}$ Left ventricular mid-systolic diameter and the respective posterior wall thickness were measured at the mid-point between the first and second heart sounds. The peak systolic shortening rate of the instantaneous cavity dimension, divided by end-diastolic diameter, gave the maximum circumferential fibre shortening velocity $\left(\mathrm{VCF}_{\max }\right) .{ }^{12}$ Heart rate was derived from the R-R intervals on the electrocardiogram.

Cardiac volumes, including stroke volume and ejection fraction, ${ }^{11}$ were calculated using the Teichholz formula for volume approximation. ${ }^{14}$ Cardiac output was estimated by multiplying stroke volume with heart rate. Total peripheral resistance ${ }^{15}$ was calculated with the formula: Peripheral resistance (dyn min $\left.\mathrm{cm}^{-5}\right)=($ mean $\mathrm{BP} / \mathrm{CO}) \times 1332$, where $\mathrm{BP}$ is arterial blood pressure and $\mathrm{CO}$ is cardiac output; mean $\mathrm{BP}$ was assumed to be diastolic BP $+1 / 3$ (systolic BP diastolic BP). Circumferential wall stress ${ }^{16}$ was estimated in left ventricular mid-systole with the formula: Wall stress $\left(\mathrm{dyn} / \mathrm{cm}^{2}\right)=(\mathrm{PD} / 2 \mathrm{~h})[1-\mathrm{D} / 8(\mathrm{D}+$ h)] $\times 1332$, where $P$ is systolic blood pressure, $D$ is left ventricular mid-systolic diameter, and $h$ is posterior wall mid-systolic thickness. The five consecutive or nearly consecutive cardiac cycles with the best technical adequacy were digitised and averaged from each recording.

\section{SYSTOLIC TIME INTERVALS}

Indirect carotid arterial pulse tracing, lead II electrocardiogram, and external phonocardiogram (filter setting 250 to $2000 \mathrm{~Hz}$ ) were recorded simultaneously using the channels for physiological signals in the Irex System II echocardiograph. The chart speed was 100 $\mathrm{mm} / \mathrm{s}$. The recordings were analysed using an $x-y$ digitiser and an Honeywell DPS 8 computer. Total electromechanical systole $\left(\mathrm{QS}_{2}\right)$, left ventricular ejection time (LVET), and pre-ejection period (PEP) were determined and averaged from 10 consecutive cycles according to standard methods. ${ }^{17}$ The systolic time intervals were further corrected for heart rate by Weissler's regression equations ${ }^{18}$ to obtain their indexed equivalents (PEPi, LVETi, $\mathbf{Q S}_{2} \mathbf{i}$ ). The PEP/ LVET ratio was calculated from uncorrected data.

NON-INVASIVE END-SYSTOLIC

PRESSURE-VOLUME RELATIONS

The relations between pressures and volumes at endsystole were analysed by calculating the systolic blood pressure/end-systolic volume ratios. It has been shown in invasive studies that the pressure-volume slope at end-systole reflects myocardial contractility, ${ }^{19}$ and recently this method has proved applicable to non-invasive studies as well..$^{20} 21$ Importantly, its simple modification, the systolic blood pressure/endsystolic volume ratio, seems to be a sensitive index of left ventricular function, even though it does not represent the actual pressure-volume slope. ${ }^{21}$

\section{NON-INVASIVE INDEX FOR ISOVOLUMIC}

PRESSURE RISE IN LEFT VENTRICLE (NIPR)

Invasive studies 2223 have shown that the peak rate of isovolumic pressure rise (peak dp/dt) in the left ventricle, divided by end-diastolic volume or circumference, is sensitive to changes in contractility. A noninvasive equivalent to it was calculated in this study by the following formula: $\mathrm{NIPR}$ ( $\mathrm{mmHg} / \mathrm{mm}$ per s) = diastolic $\mathrm{BP} /(\mathrm{PEP})$ (LVEDD), where $\mathrm{BP}$ is arterial blood pressure, PEP is pre-ejection period, and LVEDD is left ventricular end-diastolic diameter. The use of this index is based on both experimental and clinical studies. Firstly, experimental data have shown that the ratio, diastolic blood pressure/ isovolumic contraction time, correlates well with peak $\mathrm{dp} / \mathrm{dt}$ under varying loading and inotropic conditions. ${ }^{24}$ Secondly, studies in patients with acute myocardial infarction have disclosed that changes in peak $\mathrm{dp} / \mathrm{dt}$ can be reliably assessed using diastolic 
blood pressure and PEP as well as pulmonary wedge pressure to correct for major changes in end-diastolic pressure. ${ }^{25}$ The use of the non-invasive index for isovolumic pressure rise in the left ventricle may thus be particularly expedient when left ventricular function is assessed sequentially in the same subject, provided that major changes in end-diastolic pressure can be excluded.

\section{REPRODUCIBILITY}

Ten healthy volunteers took part in a methodological study set out to assess the random variation in the cardiovascular measurements. The design of this study was identical to those presented above except that no interventions were made. The subjects merely lay supine and a left ventricular echocardiogram and recordings for systolic time intervals were performed six times over a three-hour period. The recordings were analysed as presented above. Individual and group mean coefficients of variation (mean/SD) were calculated for each measured variable.

The mean coefficients of variation for end-diastolic and end-systolic dimensions were $1.3 \%$ and $1.7 \%$, respectively. The corresponding coefficients for all the other echocardiographically derived variables ranged from $2.5 \%$ (ejection fraction) to $5.7 \%$ $\left(\mathrm{VCF}_{\max }\right)$. The mean coefficients of variation for the systolic time intervals ranged from $0.9 \%$ (LVETi) to $3.7 \%$ (PEP/LVET). Analysis of variance showed a significant decreasing effect of time on LVETi $(p<$ 0.002 ). These data indicate a small random variation in the cardiovascular measurements.

BLOOD ETHANOL DETERMINATION

Ethanol was determined from venous blood by headspace gas chromatography. ${ }^{26}$

\section{STATISTICAL ANALYSIS}

The significance of the cardiovascular changes from the baseline during ethanol and control experiments was assessed, and these changes were compared mutually as well as between men and women, using analysis of variance with repeated measures. Student's $t$ test for paired observations was used when appropriate. The results are given as means \pm SEM.

\section{Results}

\section{EFFECTS OF SEX}

No statistically significant differences between men and women were found either in blood ethanol concentrations or in the cardiovascular changes after ethanol ingestion, neither were any sex differences noted in the control experiment. The data were therefore processed further as one group.

\section{BLOOD ETHANOL CONCENTRATIONS}

The blood ethanol curve is shown in Fig. 1. The peak mean ethanol concentration was observed 30 minutes after ingestion and was $24.6 \pm 0.9 \mathrm{mmol} / \mathrm{l}(112 \pm 4$ $\mathrm{mg} / 100 \mathrm{ml}$ ).

\section{CARDIOVASCULAR CHANGES IN CONTROL EXPERIMENT}

The data are shown in Fig. 2 to 5 and in the Table. Significant changes were observed in each of the systolic time intervals and the PEP/LVET ratio (Table). In addition, diastolic blood pressure rose from $77 \pm 2$ $\mathrm{mmHg}$ before juice to $80 \pm 2 \mathrm{mmHg}$ in the 180 minute measurements $(p<0.01$, Fig. 2). The increases in systolic blood pressure, stroke volume, ejection fraction, and non-invasive index for isovolumic pressure rise in the left ventricle, during or

Table Heart rate and systolic time intervals before and after ethanol and during control experiment

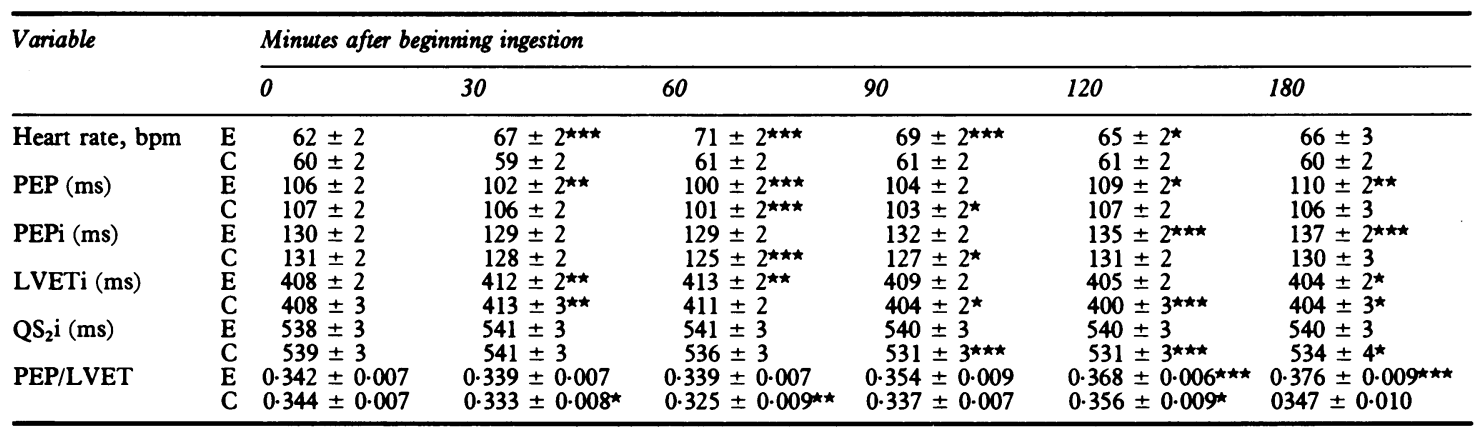

Results are means \pm SEM. E, ethanol $1 \mathrm{~g} / \mathrm{kg}$ by mouth within 60 mintues; $\mathrm{C}$, control experiment (isovolumic amount of juice within 60 minutes); PEP, pre-ejection period; PEPi, PEP corrected for heart rate; LVET, left ventricular ejection time; LVETi, LVET corrected for heart rate; $\mathrm{QS}_{2} \mathrm{i}$, total electromechanical systole corrected for heart rate. Significance of changes from the 0 -measurements: ${ }^{\star}, \mathrm{p}<0.05 ; \star \star, p<$ $0.01 ; \star \star \star, \mathrm{p}<0.001$. 


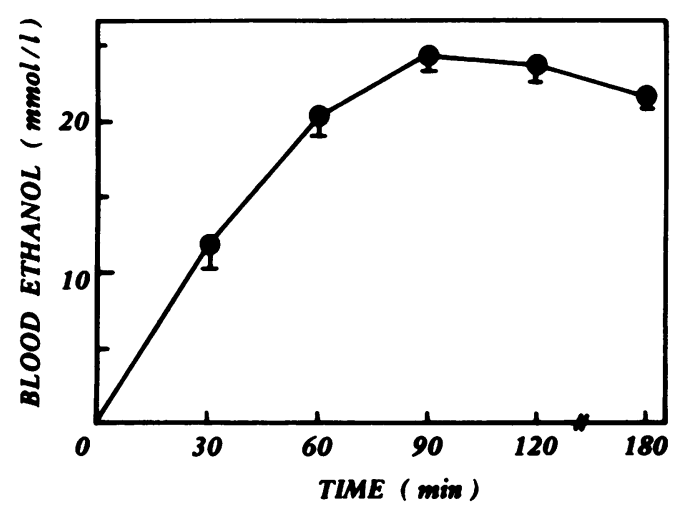

Fig. 1 Blood ethanol curve. The bars indicate standard errors. The conversion factor from monoll to $\mathrm{mg} / 100 \mathrm{ml}$ is 4.5 .
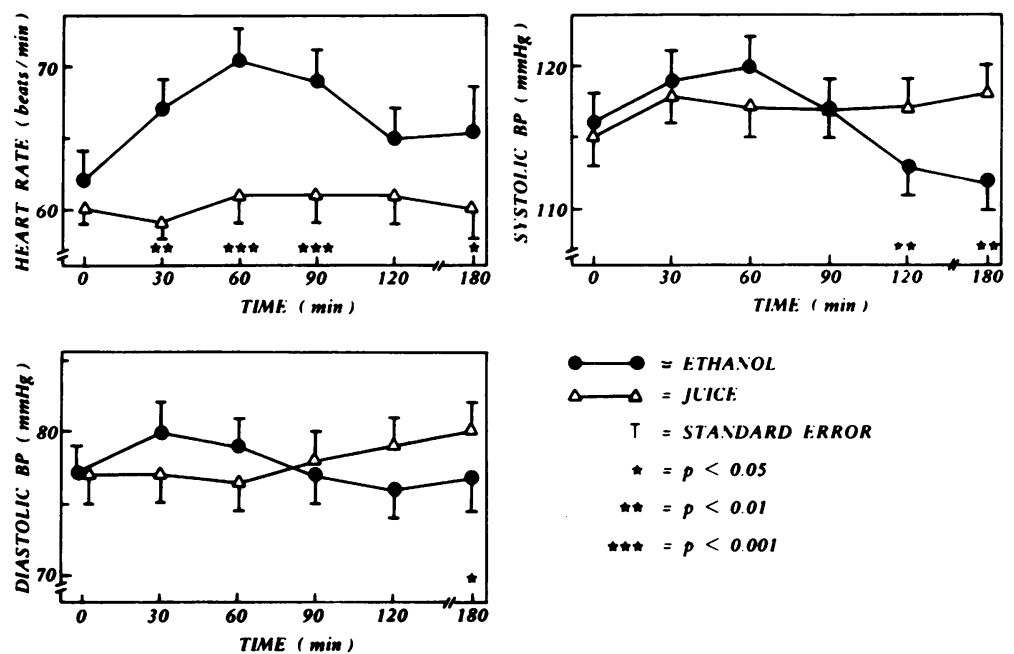

$$
\begin{aligned}
\longrightarrow & =\text { ETHANOL } \\
\Delta & =\text { JLICE } \\
T & =\text { STANDARD ERROR } \\
& =p<0.05 \\
& =p<0.01 \\
\star & =p<0.001
\end{aligned}
$$

Fig. 2 Effects of ethanol on heart rate and blood pressure (BP). Ethanol $(1 \mathrm{~g} / \mathrm{kg})$ or an isovolumic amount of juice was ingested within 60 minutes after the control measurements. The statistical significancies refer to comparisons between changes from the baseline in the ethanol and control experiments.

directly after juice ingestion (Fig. 2 to 4 ), were of weak statistical significance $(\mathrm{p}<0.05)$ by paired $t$ test, even though not by analysis of variance.

\section{EFFECTS OF ETHANOL}

The cardiovascular responses to ethanol ingestion were considered to be the results of the effects of ethanol per se, if they differed significantly (analysis of variance) from the respective responses in the control test. These results are given in Fig. 2 to 5.

Ethanol increased heart rate by $15 \%$ (maximal mean change) and caused a late $3 \%$ decrease in systolic blood pressure (Fig. 2). The difference in diastolic blood pressure reflected the increase of this variable during the control experiment. Cardiac out- put increased by $17 \%$ during ethanol ingestion and peripheral resistance decreased simultaneously by $15 \%$ (Fig. 3). During the declining blood ethanol end-diastolic diameter shortened by $2 \%$ and, concurrently, stroke volume and circumferential wall stress were reduced by $7 \%$ and $5 \%$, respectively. The echocardiographic indices of left ventricular function (Fig. 4) showed no significant effects of ethanol per se, even though $\mathrm{VCF}_{\max }$ and non-invasive index for isovolumic pressure rise in left ventricle increased from their pre-ethanol levels during ingestion $(p<$ 0.01 and $<0.05$, respectively).

The changes in each of the systolic time intervals and the PEP/LVET ratio differed at some time point during the ethanol and control experiments (Fig. 5). 

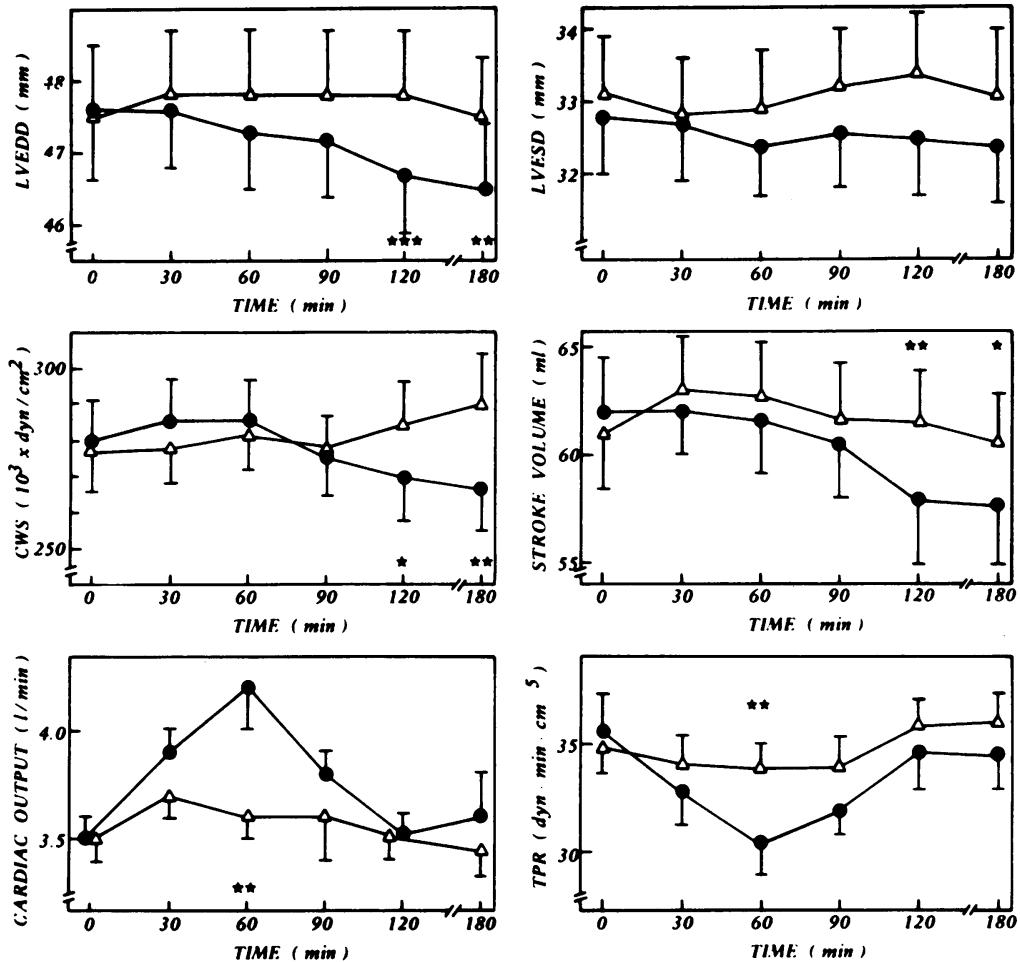

Fig. 3 Effects of ethanol on left ventricular size and wall stress as well as on some haemodynamic variables. For symbols and experimental conditions, see Fig. 2. LVEDD, left ventricular end-diastolic diameter; LVESD, left ventricular end-systolic diameter; $C W S$, circumferential wall stress; TPR, total peripheral resistance.
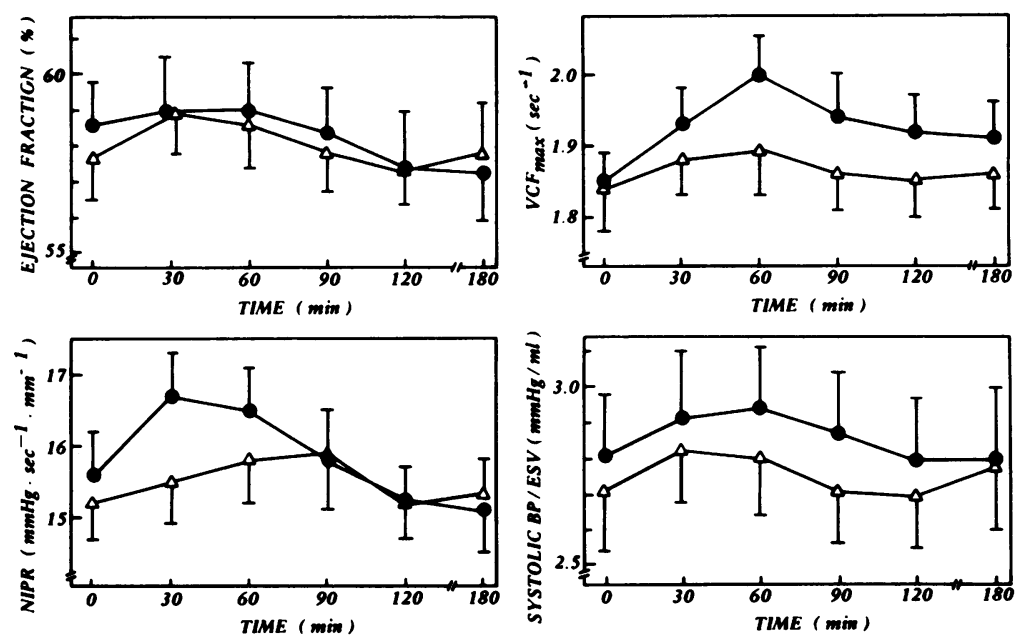

Fig. 4 Effects of ethanol on the indices of left ventricular function. For symbols and experimental conditions, see Fig. 2. VCF max, maximal circumferential fibre shortening velocity; NIPR, non-invasive index for the isovolumic pressure rise in left ventricle (see Methods); BP, blood pressure; ESV, end-systolic volume. 

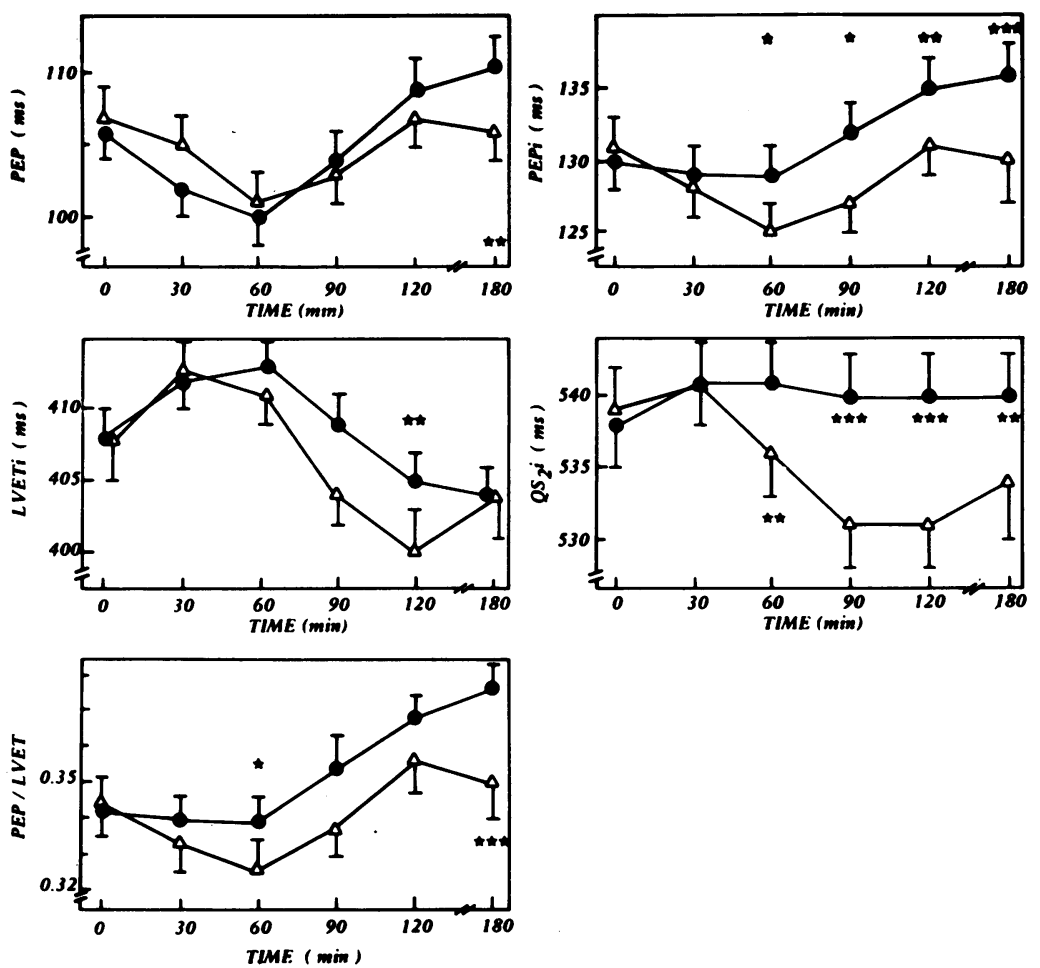

Fig. 5 Effects of ethanol on the systolic time intervals. For symbols and experimental conditions, see Fig. 2. PEP, pre-ejection period; PEPi, PEP corrected for heart rate; $L V E T$, left ventricular ejection time; LVETi, LVET corrected for heart rate; $Q S_{2} i$, total electromechanical systole corrected for heart rate.

\section{Discussion}

One obvious source of discrepant views about the acute cardiac effects of alcohol is that the essential conceptual disparities between cardiac performance and myocardial performance have not always been properly considered. Myocardial performance, its contractility, refers to the active inotropic state of the cardiac muscle and is independent of the loading conditions of the left ventricle. This entails that cardiac performance as a pump is not synonymous with myocardial performance and, in fact, in normal heart stroke output depends primarily on peripheral factors and their influence upon preload and afterload, instead of the exact level of myocardial contractility. ${ }^{27}$ An important corollary of this principle is that a change in left ventricular function - or in its noninvasive indices - denotes altered contractility only in so far as it is independent of simultaneous changes in loading conditions. Fortunately, echocardiography provides information about changes in preload (enddiastolic diameter) and afterload (systolic wall stress) to allow for these extramyocardial determinants of cardiac performance.

ETHANOL-RELATED CARDIOVASCULAR CHANGES The cardiovascular effects of ethanol were conspicuously different during the increasing and decreasing blood ethanol phases. Haemodynamics during the increasing blood ethanol were characterised by a positive chronotropic change as well as by a decrease in peripheral resistance and an increase in cardiac output. These findings are in accordance with the respective data from previous studies, in which minute volume was estimated by dye-dilution techniques. 2829 Peripheral arterial vasodilatation accounts best for the reduction in peripheral resistance and also explains, via increased venous return, the failure of left ventricular dimensions to shorten during ethanol ingestion despite the highly significant rise in heart rate. ${ }^{30}$

During the decreasing blood ethanol the dominant change was a reduction in preload, as shown by the progressive shortening of end-diastolic diameter. ${ }^{31}$ The decrease in afterload was probably secondary to 
the preload change. ${ }^{31}$ The idea that alcohol may acutely alter loading conditions has been little entertained in previous investigations, even though the data of Delgado et al. ${ }^{6}$ and those of Timmis et al. ${ }^{10}$ show significant shortening of end-diastolic dimension after ethanol ingestion. Thus, alcohol-induced changes in cardiac performance, for example increases in PEP and PEP/LVET, 45 have been expounded by assuming myocardial depression without accurately knowing whether left ventricular size or end-diastolic pressure were simultaneously altered. True, the diminution of stroke volume as well as the increases in PEP and PEP/LVET indicate ethanol-induced cardiac depression also in the present study. Yet, the simultaneous other data showed that these changes were merely reflections of a downward shift on the Frank-Starling curve; stroke volume and the systolic time intervals are highly sensitive to preload alterations in normal hearts. ${ }^{31} 32$ Myocardial contractility was not detectably impaired.

The origin of the reduction in preload remains speculative. It did not result, however, merely from the rate-dependency of preload since the rise in heart rate during the decreasing blood ethanol was too small to account for the total shortening of end-diastolic diameter. ${ }^{30}$ Thus, either the diuretic activity of ethanol ${ }^{33}$ or venous pooling, or both, may have contributed to that change. In a recent study an analogous finding, alcohol-induced reduction in pulmonary wedge pressure in patients with severe heart failure, was tentatively ascribed to increased venous capacitance. $^{2}$

\section{SYSTOLIC TIME INTERVALS DURING CONTROL EXPERIMENT}

Surprisingly, each of the systolic time intervals was significantly altered during the control experiment. The decreases of PEP, PEPi, and PEP/LVET during juice ingestion, as well as the simultaneous increase in LVETi, indicate enhanced cardiac performance ${ }^{17}$ and are consonant with the simultaneous increasing tendency in the echocardiographic indices of left ventricular function. Whatever its cause, a volume effect or autonomic reflexes evoked by the ingestion of cold juice, this observation shows the sensitivity of the systolic time intervals and emphasises the importance of controlling. The late abbreviations of LVETi and $\mathrm{QS}_{2} \mathbf{i}$, on the other hand, resulted most probably from the diurnal shortening tendency of these intervals. ${ }^{34} 35$ This relatively little recognised phenomenon has been ascribed to a circadian rhythm in the secretion of catecholamines, ${ }^{35}$ even though other authors have been doubtful about the role of circulating adrenaline or noradrenaline. ${ }^{36}$ It is hard to give credit to catecholamine involvement from the present data either, since the shortening of LVETi and $\mathrm{QS}_{2} \mathrm{i}$ were maximal at a time point when no changes were ${ }^{c}$ observable in heart rate or in any of the echocardio- $\overrightarrow{\vec{s}}$ graphic variables.

The PEP/LVET ratio was significantly increased at the time of maximal LVETi shortening during the control experiment. This index has been widely used $\vec{\Phi}$ as a measure of myocardial contractility, for example in alcohol studies. ${ }^{4-6}$ On the other hand, rate- -5 independent changes in $\mathrm{QS}_{\mathbf{2}}$ have been recently advo- 0 cated for assessment of inotropic changes as well, pro- $-\overrightarrow{-}$ vided the loading conditions are not "radically" altered and the measurements are made "during a single day". ${ }^{37}$ Paradoxically enough, the shortening of $\mathrm{QS}_{2} \mathrm{i}$ and the increase in PEP/LVET during the control experiment suggested simultaneously an improvement and an impairment of contractility $\vec{A}$ respectively, when myocardial performance byo echocardiography was actually unaltered.

ETHANOL-RELATED CHANGES IN SYSTOLIC TIME 율 INTERVALS

The dissimilar late changes in PEP, PEPi, and PEP $\mathscr{K}$ LVET during the ethanol and control experiments related to the ethanol-induced decrease in left ventricular filling, as contrasted with unchanged preload during the control test. The early post-drink differ-O ence in PEPi is more difficult to make out. It may, however, simply reflect the significant disparity in the heart rate responses, since recent evidence suggest ${ }^{\circ}$ that PEP need not be corrected for heart rate. ${ }^{37-39} \mathrm{On}$ ? the other hand, PEP/LVET is, contrary to a veryö common misconception, directly rate dependent in intraindividual studies, ${ }^{37} 39$ which explains why PEP/LVET was not decreased during ethanol ingestion. The conspicuous failure of $\mathrm{QS}_{2} \mathrm{i}$ to shorten after ethanol remains unaccountable, simply because the genesis of this change in the control experiment coulds not be inferred from the obtained data.

The present study shows expressly the intricacy of factors involved in the changes of systolic time inter- -3 vals and the problems in their interpretation. Theo major pitfalls seem to be the diurnal variation and the fact that if the mere time events of the cardiac cycle are measured no means exist to quantify the role of preload changes to the results obtained. Moreover, incorrect use of the regression equations may also lead to erroneous conclusions. All things considered, this method should not be used without adequate controlling and without independent information about preload in studying changes in cardiac performance, le alone assessment of changes in myocardial contractils ity.

\section{Conclusions}

This investigation emphasises the significance of the 
peripheral circulatory actions of ethanol and their influence on the extramyocardial determinants of cardiac performance. In modest doses ethanol decreases peripheral vascular resistance and increases heart rate as well as cardiac output during the rising blood ethanol, and reduces preload and afterload during the declining blood ethanol, without impairing myocardial performance. These conclusions do not rule out adverse myocardial effects from alcohol in large doses or as a sequel to long-term over-indulgence.

I am grateful to Drs Juhani Heikkilä and Reino Ylikahri for assistance and advice during this investigation and in preparing the manuscript.

\section{References}

1 Portal RW. Alcoholic heart disease (leading article). Br Med f 1981; 283: 1202-3.

2 Greenberg BH, Schutz R, Griswold HE. Acute effects of alcohol on cardiac performance in patients with congestive heart failure. Clin Res 1981; 29: 200A.

3 Gould L, Zahir M, DeMartino A, Gomprecht RF. Cardiac effects of a cocktail. $\mathcal{F A M A}$ 1971; 218: 1799-802.

4 Ahmed SS, Levinson GE, Regan TJ. Depression of myocardial contractility with low doses of ethanol in normal man. Circulation 1973; 48: 378-85.

5 Gould L, Reddy CVR, Goswami K, Venkatamaran K, Gomprecht RF. Cardiac effects of two cocktails in normal man. Chest 1973; 63: 943-7.

6 Delgado CE, Fortuin NJ, Ross RS. Acute effects of low doses of alcohol on left ventricular function by echocardiography. Circulation 1975; 51: 535-40.

7 Van Voorhees L, Gottdiener JS, Gay J, DiBianco R, Maloney DL, Fletcher RD. The effects of alcohol on left ventricular relaxation and systolic function in normal subjects: echocardiographic assessment by computer assisted analysis of wall velocity. Clin Res 1981; 29: 248 A.

8 Van Voorhees L, Gottdiener JS, DiBianco R, et al. Effects of alcohol ingestion on left ventricular function in normal nonalcoholic subjects. Clin Res 1981; 29: 248A.

9 Wu CF, Sudhakar M, Jaferi G, Ahmed SS, Regan TJ. Preclinical cardiomyopathy in chronic alcoholics: a sex difference. Am Heart $\mathcal{F}$ 1976; 91: 281-6.

10 Timmis GC, Gordon S, Ramos RG, Gangadharan V. The relative resistance of normal young women to ethanolinduced myocardial depression. Angiology 1979; 30: 733-43.

11 Feigenbaum H. Echocardiography. 3rd ed. Philadelphia: Lea \& Febiger, 1981: 119-36.

12 Upton MT, Gibson DG. The study of left ventricular function from digitized echocardiograms. Progr Cardiovasc Dis 1978; 20: 359-84.

13 Roelandt J, Gibson DG. Recommendations for standardization of measurements from $\mathbf{M}$-mode echocardiograms. Eur Heart f 1980; 1: 375-8.

14 Teichholz LE, Kreulen T, Herman MV, Gorlin R. Problems in echocardiographic volume determinations: echocardiographic-angiographic correlations in the pres- ence or absence of asynergy. Am $\mathcal{J}$ Cardiol 1976; 37: 7-11.

15 Stefadouros MA, Dougherty MJ, Grossman W, Craige E. Determination of systemic vascular resistance by a noninvasive technique. Circulation 1973; 47: 101-7.

16 Ratshin RA, Rackley CE, Russell RO Jr. Determination of left ventricular preload and afterload by quantitative echocardiography in man. Circ Res 1974; 34: 711-8.

17 Lewis RP, Rittgers SE, Forester WF, Boudoulas H. A critical review of the systolic time intervals. Circulation 1977; 56: 146-58.

18 Weissler AM, Harris WS, Schoenfeld CD. Systolic time intervals in heart failure in man. Circulation 1968; 37: $149-59$.

19 Grossman W, Braunwald E, Mann T, MacLaurin LP, Green LH. Contractile state of the left ventricle in man as evaluated from end-systolic pressure-volume relations. Circulation 1977; 56: 845-52.

20 Marsh JD, Green LH, Wynne J, Gohn PF, Grossman W. Left ventricular end-systolic pressure-dimension and stress-length relations in normal human subjects. $A m \mathcal{F}$ Cardiol 1979; 44: 1311-7.

21 Dehmer GJ, Lewis SE, Hillis LD, Corbett J, Parkey RW, Willerson JT. Exercise-induced alterations in left ventricular volumes and the pressure volume relationship: a sensitive indicator of left ventricular dysfunction in patients with coronary artery disease. Circulation 1981; 63: 1008-18.

22 Mason DT. Usefulness and limitations of the rate of rise of intraventricular pressure $(\mathrm{dp} / \mathrm{dt})$ in the evaluation of myocardial contractility in man. Am $\mathcal{F}$ Cardiol 1969; 23: 516-27.

23 Quinones MA, Grasch WH, Alexander JK. Influence of acute changes in preload, afterload, contractile state and heart rate on ejection and isovolumic indices of myocardial contractility in man. Circulation 1976; 53: 293-302.

24 Landry AB Jr, Goodyer AVN. Rate of rise of left ventricular pressure. Indirect measurement and physiologic significance. Am f Cardiol 1965; 15: 660-4.

25. Diamond G, Forrester JS, Chatterjee K, Wegner S, Swan HJC. Mean electromechanical $\Delta \mathrm{p} / \Delta \mathrm{t}$. An indirect index of the peak rate of rise of left ventricular pressure. Am $\mathcal{F}$ Cardiol 1972; 30: 338-42.

26 Eriksson CJP, Sippel HW, Forsander OA. The determination of acetaldehyde in biological samples by headspace gas chromatography. Anal Biochem 1977; 80: 116-24.

27 Braunwald E. Assessment of cardiac performance. In: Braunwald E, ed. Heart disease. Philadelphia: WB Saunders, 1980: 472-92.

28 Riff DP, Jain AC, Doyle JT. Acute hemodynamic effects of ethanol on normal human volunteers. Am Heart $\mathcal{Y}$ 1969; 78: 592-7.

29 Juchems $R$, Klobe $R$. Hemodynamic effects of ethyl alcohol in man. Am Heart $\mathcal{Y} 1969 ; 78$ : 133-5.

30 DeMaria AN, Neumann A, Schubart PJ, Lee G, Mason DT. Systematic correlation of cardiac chamber size and ventricular performance determined with echocardiography and alterations in heart rate in normal persons. $A m \mathcal{F}$ Cardiol 1979; 43: 1-9.

31 Sonnenblick EH, Strobeck JE. Derived indexes of ventricular and myocardial function. N Engl f Med 1977; 
296: 978-82.

32 Stafford RW, Harris WS, Weissler AM. Left ventricular systolic time intervals as indices of postural circulatory stress in man. Circulation 1970; 41: 485-92.

33 Ritchie JM. Ethyl alcohol. In: Goodman LS, Gilman A, eds. The pharmacological basis of therapeutics. 5th ed. New York: Macmillan, 1975: 137-46.

34 Weissler AM, Kamen AR, Bornstein RS, Schoenfeld $\mathrm{CD}$, Cohen $\mathrm{S}$. The effect of deslanoside on the duration of the phases of ventricular systole in man. Am $\mathcal{F}$ Cardiol 1965; 15: 153-61.

35 Wertheimer L, Hassen AZ, Delman AJ. The 24hour (circadian) rhythm of the cardiovascular system (abstract). Clin Res 1972; 20: 404.

36 Aronow WS, Harding PR, DeQuattro V, Isbell $M$. Diurnal variation of plasma catecholamines and systolic time intervals. Chest 1973; 63: 722-6.
37 Johnson BF, Meeran MK, Frank A, Taylor SH. Systolic time intervals in measurement of inotropic response to drugs. Br Heart f 1981; 46: 513-21.

38 Kesteloot $\mathbf{H}$. Limitations of systolic time intervals for evaluation of cardiac function. In: List WF, Gravensteir JS, Spodick DH, eds. Systolic time intervals. Berlin Heidelberg, New York: Springer-Verlag, 1980: 30-5. 요

39 Ferro G, Ricciardelli B, Sacca L, et al. Relationship ben tween systolic time intervals and heart rate during atriar? or ventricular pacing in normal subjects. $\jmath_{p n}$ Hear $\mathscr{F}$ 1980; 21: 765-71.

Requests for reprints to Dr Markku Kupari, Car diovascular Laboratory, Helsinki University Centraf Hospital, SF-00290 Helsinki 29, Finland. 